\title{
Reference-Bibliographers in the College Library
}

One approach to making a college library more relevant, dynamic, and intelligible is to employ specialists with broad subject competence, thoroughly familiar with the terminology, bibliographic tools, and major writings of several related disciplines. These subject specialists or reference-bibliographers provide reference and instructional services, and serve as coordinators between academic departments and the library. A significant increase in the quality of library service is attained with reference-bibliographers both building and interpreting the collection. The reference-bibliographer concept is examined from several perspectives: historical antecedents; relationship to the academic setting; and the authors experience with a staff of subject specialists at a predominantly undergraduate college library during 1969-1972.

W

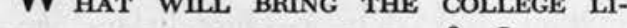
BRARY Collectror to LIFE? One approach within our grasp is a commitment to educate and to employ subject specialists, preferably called referencebibliographers. Such a librarian would function in the capacities of reference librarian, bibliographic instructor, and selection specialist in a relatively broad area such as the social sciences, humanities, or sciences. He would not specialize in one narrow field, but rather possess competence in several related disciplines with knowledge of terminology, bibliographic tools, and major writing.

The bibliographer as book/journal selector has been a staple in many large public and university libraries for several decades. Herman Fussler, formerly

Selby U. Gration is director of libraries, SUNY Cortland, and Arthur P. Young is research associate, Library Research Center, University of Illinois (formerly head of reader services, SUNY Cortland). of the University of Chicago library, and Cecil K. Byrd, Indiana University library, have described the responsibilities and value of subject specialists in a university setting. ${ }^{1}$ From the available literature, however, it appears that the major tasks of university bibliographers are related to selection, with only occasional attention to reference work or formal instruction. In contrast, the college reference bibliographer devotes approximately equal commitment to reference and selection duties, and increases accessibility by placement in the reference or public services department. The reference-bibliographer possesses more specialized subject competencies than the generalist college reference librarian and a broader subject area mandate than some university bibliographers. Participation in bibliographic instruction is a required activity for the reference-bibliographer.

Service and substantive knowledge of a cognate discipline are compatible, in- 
terrelated requirements for the next generation of college reference librarians. Robert Haro has written about a Renaissance bibliographer who performs as selector, reference librarian, and teacher. It is toward his idealized model that we have journeyed. ${ }^{2}$

\section{Phantasmic Species}

In a perceptive speech at the Louisiana State University library, Richard $\mathrm{H}$. Dillon asked where the cadre of library subject specialists could be found. With regret, he concluded that subject specialists were almost a phantasmic species, and that for many years in librarianship there has been

... a subliminal understanding that we are servants of scholarly men, hand-maidens of culture, not co-equals with those who research and create. This self-limitation has acted as a governor on the speed of our progress, as blinders on our vision. We can be the peers of our patrons, however serious and studious they may be, if we set out to create a partnership. But we must bring plenty of collateral in the form of education, training, knowledge. ${ }^{3}$

Dillon was deploring the myth of the generalist librarian who cannot relate to faculty and students beyond the veneer of bibliographic sources, and who does not possess the advanced study required for quality acquisition decisions and specialized reference work.

In a recent report commissioned by the National Academy of Sciences and the Social Science Research Council, the call for library subject specialists is considered a priority:

Most major libraries have made major advances in automated services and have hired personnel competent in this area. Similar progress has not been made, however, in training curatorial librarians who combine knowledge of subject and area with skill in library techniques and can thus work with scholars in planning and executing programs responsive to new intellectual interests. Specialized acquisitions personnel remain one of the weakest links in the library system. Especially needed are persons who are themselves scholars and thus aware of innovations in scholarship, so that they can compensate by their knowledge and interests for the inevitable gaps in faculty initiative. All the great libraries have had people of this kind, but they are becoming scarcer-partly because the best of them are diverted into administrative or teaching jobs, partly because the salaries for this kind of work are not commensurate with the talent and contributions of these specialists. There is clearly a need here to define and institutionalize a new career with sufficient rewards in money and prestige to attract the talent required. ${ }^{4}$

Although the report tends to focus on larger institutions, it also applies to the middle-sized academic institution. Service quality should not be primarily differentiated by institutional size. In fact, a small- or medium-size college may be more in need of three or four reference-bibliographers than a major university in order to make discriminating selection and to provide the bibliographic instruction possible in a closely knit community of scholars.

\section{Clio's SHadow}

A brief foray into library history reveals antecedent ideas and movements that have influenced the reference-bibliographer concept. In some respects it draws from the scholar-librarian tradition of a former age. The early history of American librarianship demonstrates that many individuals, attracted to library work from established scholarly disciplines, profoundly contributed to the substance and stature of the profession. The readers' ' advisor movement, which bloomed in the 1920s and 1930s, emphasized the assessment of community needs and the discriminating recommendation of materials to public li- 
brary patrons. Bibliographic skills were coupled with a knowledge of the literature. Retrieval without the capacity for qualitative advice on the merits of sources was considered a mechanistic facility.

The Library-College movement has contributed to the reference-bibliographer concept by aiming at a union of bibliographic expertise and teaching competence. Formal communication of bibliographic knowledge, particularly to advanced students, is a linkpin in the reference-bibliographer's inventory of tasks. Responding to user inquiries, however creative and skillful, is still an essentially passive activity. A planned, aggressive instructional program is an indispensable corollary to answering random inquiries as it provides the serious library user with the bibliographic context to articulate future questions with precision.

\section{RESPONSIVE LIBRARIANSHIP AND FacUlty Status}

Responsive academic librarianship for the 1970s and beyond must be based on a thorough comprehension of curricular trends and the impact of innovations in educational/informational technology on user requirements. Greater emphasis on independent study, less reliance on lectures, increased use of nonprint materials, and a more sophisticated student population have already appeared as significant educational forces in many colleges and universities. Although the influence of these trends on academic librarianship is as yet unclear, in this period of major educational introspection and experimentation, it is imperative that librarians begin to participate in faculty and administrative decision-making processes regarding curriculum modification, facilities, enrollment, and budgetary allocations. A responsive posture cannot be attained by hastily reacting to every shift in curriculum and instructional strategy after it has been implemented. Librarians' long-range contribution to the academic community requires an anticipatory posture that attempts to foresee the evolving information requirements of students and faculty, and thereby to enhance the bibliographic dimension in the learning environment.

It is one thing to proclaim alliance with the faculty and quite another to gain their confidence and respect. To convey the value of proficiency in information-seeking strategies and bibliographic sources to faculty requires that the instructor first perceives the librarian as an intellectual peer. Many professors are blithely unconcerned about developing student competencies in the use of library resources and accept bibliographic sources and documentation of inferior quality. To achieve a more symbiotic relationship with faculty and students, librarians must attain a comprehensive knowledge of one or more scholarly disciplines and become familiar with the dynamics of scholarly research. Faculty can relate to the librarian who is conversant with different schools of thought as well as primary literature in his discipline, and who can recommend a new title for his perusal. In this role the librarian can strive for a complementary, counselor relationship, rather than a competitive one. Satisfaction of the instructor's informational needs will generate mutual respect and an awareness of the librarian's capacity to serve faculty and students.

Responsive librarianship may also be enhanced by the current quest for faculty status by librarians. Role and status in a social system influence relations among members of groups. As information mediators, librarians are an integral part of the educative process; yet it will be the faculty who will judge the merits of their entry into the professoriate. If the lack of faculty status for librarians lowers faculty perceptions of 
their worth, then librarians must couple their desire for faculty integration with quality performance and educational attainments beyond the basic professional degree. It is suggested that faculty, students, and administrators will relate more beneficially to those academic librarians (and vice versa) with faculty status, multiple advanced degrees, foreign language proficiency, and scholarly specializations.

\section{Toward a New Librarian}

The following sections describe the reference-bibliographer concept in terms of job responsibilities, organizational structure, and impact on library services. Comments are derived from the authors' experience in designing, implementing, and evaluating a staff of four reference bibliographers, each with at least two master's degrees, at the State University of New York, College of Cortland. Previously the library employed only general reference librarians.

\section{Job Responsibilities}

Amalgamation of the acquisition and reference functions is the premise for the position of the reference-bibliographer. With the slow but unmistakable shift of selection responsibility from faculty to library, it is increasingly evident that one or two generalist acquisition staff members cannot do justice to all fields covered by the curriculum as well as supervise clerical personnel in the search/order process. Furthermore, the traditional base of acquisition personnel in technical services isolates them from the locus of information transfer in the public service area. It is difficult to maintain a sensitivity to the curriculum and to evolving informational needs with such a locational constraint.

Because faculty-dominated selection is often sporadic and lacking in sustained quality, faculty input should be cultivated, particularly in esoteric sub- ject areas. Academic librarians must reverse their frequent abdication of selection decisions to those who are neither trained nor inclined to recommend titles on a sound bibliographical basis. All too often, generalist acquisition personnel have reviewed faculty requests as sacred, without due weight given to present holdings, curriculum requirements, and circulation data. An intensive consideration of faculty recommendations and internal selections takes considerable time, both clerical and professional, and above all requires an intimate day-today knowledge of collection parameters and use. In addition, determination of whether a title is a valuable contextual addition to the collection requires qualitative judgments which depend on considerable knowledge of subject literatures. It is doubtful that most generalist acquisition librarians possess suffcient subject competencies for this highly discriminative task.

The road toward faculty acceptance of library control over collection development may be more rocky than some believe. In an incisive empirical analysis of university area specialist bibliographers, Dr. Robert Stueart found significant role strain between librarians and faculty over selection and weeding activities. Since 60 percent of his bibliographer sample possessed at least two master's degrees, thus comprising an elite librarian subgroup, it is discouraging to find such role dissonance and inadequate articulation by librarians of their professional identity and mission. ${ }^{5}$

Libraries have not come to grips with collection growth limits. With the rapid expansion of undergraduate collections, one can readily see that even a somewhat attenuated growth rate cannot go on forever. Librarians have failed to communicate to college administrators, trustees, and legislators the importance of continuous acquisitions without infinite collection expansion. Rapid growth periods are not usually accompa- 
nied by equally active weeding programs: the knowledge explosion is paralleled by knowledge obsolescence, and attention to the latter is crucial to ensuring that college collections do not become bibliothecal mausoleums. Only subject-competent librarians can intelligently discard and only those with a sensitivity to user needs and curriculum objectives can determine multiple copy requirements. Many librarians tend to avoid multiple copies as they cannot judge between the significant and the mediocre. With more liberal circulation periods, more users, and numerous studies which indicate that most libraries circulate only a fraction of their holdings, more multiple copy decisions should be made by libraries which serve undergraduates.

Reference-bibliographers purchase materials in all media formats. Disciplinary interrelationships are emphasized over format distinctions. Although media experts are consulted for specialized media materials and equipment requirements, selection responsibility in each subject area for recordings, books, and journals, etc., is placed under the unified control of a reference-bibliographer. Uncoordinated selection criteria by format are therefore resisted. One outgrowth of this integrated approach to collection development has been our decision to apportion block amounts derived from quantitative criteria to each subject area, but without stringent internal guidelines as to monies for books, journals, or nonprint resources. This approach recognizes that each discipline has differing bibliographic requirements which only the reference-bibliographer can interpolate.

Reference service, along with selection, is a key component of the reference-bibliographer program. Although empirical data is lacking, it is probably fair to assume that most academic libraries provide satisfactory ready-refer- ence service. However, when a user inquiry elevates to a level requiring discriminative knowledge of bibliographic instruments and the literature itself, the quality of performance may be inadequate. Patrick Wilson contrasts the bibliographical consultant with the bibliographical aide in order to define the goals of the bibliographer. The bibliographical consultant is a creative hunter fully conversant with bibliographic tools, and at the same time, knowledgeable about the major writings in one or more fields. Capable of mediating between user, bibliographic apparatus, and text, he can therefore make interpretive judgments and provide substantive advice. In contrast, the bibliographic aide, however familiar with bibliographic sources, is a drone incapable of discerning beyond the imperfect representation of recorded knowledge. It is that one step beyond that yields the qualitative difference. ${ }^{6}$

\section{Organizational Configuration}

Placement of the reference-bibliographers in the reader services department to ensure maximum visibility and user interaction is an essential consideration. Extrication of the selection function from technical processes is a sine qua non of the reference-bibliographer concept. The traditional assignment of selection staff in a nonpublic service department severely reduces the chances for user feedback; often places the selector in the supervision and performance of nonprofessional routines; and makes it difficult for the selector to reach out beyond his acquisitive function into instructional or counselor activities. As a reference-bibliographer unit requires supervision, a new position of collection development librarian was instituted. This individual was responsible for generating and implementing collection development policies, budget allocations, and functionally supervis- 
ing the reference-bibliographers' selection activities. The collection development librarian also supervised the bibliographic searching and verification of all orders prior to final typing in the order department. The transferral of selection and searching functions to the collection development staff transformed the acquisition department in technical services to an order section. Although a minimal hierarchical relationship was provided, the reference-bibliographers and collection development librarian related to each other in a collegial context, stressing the consensus approach to decision making. Both the collection development librarian and the reference-bibliographers (in their reference capacity only) reported directly to the reader services director. Dual reporting based on function proved a workable administrative arrangement because the policy-making process was dedicated to participative management.

Implementation of a smoothly running collection development unit requires a pragmatic, evolutionary approach and a maximum of patience and teamwork. Realigning functions to a new location, redesigning work flow, and modifying traditional staff relationships takes time and a library-wide commitment to innovation. Several problems required continual surveillance. As the library tightened control over selection responsibility, some faculty complained that not every request was sailing through as before. A major liaison effort was undertaken to explain the new collection development program through visits by each bibliographer to the departments under his purview. As not every reference-bibliographer was fully committed to the instructional dimension, a little prodding was required. Appreciative faculty and student reactions to their initial presentations dispelled any lingering hesitancy. The tend- ency of bibliographers to sometimes overbuy in their specialties was monitored by the collection development librarian.

It soon became apparent that the reference-bibliographers could not be assigned to reference work beyond a reasonable time limit if they were to cope with their formidable multitask responsibilities. To ensure that each bibliographer would not have mandatory desk coverage in excess of fifteen hours per week, an experiment in the use of student reference assistants was launched. The use of student assistants was deemed valid in light of numerous studies which indicate the high proportion of locational and ready-reference types of questions. Several upper-level undergraduate students were given intensive tutorials in reference practice and sources, and together with bibliographer back-up, provided valuable release time for the librarians to pursue their professional activities. ${ }^{7}$

\section{Impact on Services and Collection}

With the installation of four subject specialists, several improvements emerged. The referral of tough questions between bibliographers was encouraged and occurred frequently. Contacts among the reference-bibliographers, and between them and the library user, were facilitated by the close proximity of the collection development office to the reference desk. Participation in selection, over time, produced an intimate knowledge of a major segment of the collection and resulted in a greater number of specific title recommendations to users. After the instructional program gained momentum, more students, particularly in advanced courses, returned to ask for assistance from a bibliographer by name. By the end of the second year, each reference-bibliographer was teaching ten or more advanced bibliographic sessions annually. 
The quantity of introductory orientations also climbed. Faculty, too, started to recommend to students a certain bibliographer for specialized problems.

The reference-bibliographers have brought a new personalized dimension to the often impersonal, sanitized reference function. Increased use of book reviews in scholarly journals and frequent bibliographer interaction with library users have upgraded collection quality and pertinence. Selections generated by the bibliographers have reflected a more rigorous assessment of curricular trends, collection holdings, multiple copy needs, and literature obsolescence.

\section{ConcLusion}

If libraries are committed to exercising creative control over their collections and to moving beyond superficial information transfer, present service objectives and staffing patterns must be re-examined. Reference-bibliographers are one approach to providing greater educational depth and diversity of background to a college reference staff. The amalgamation of reference and selection into one position should upgrade the qualitative performance of each activity. A corps of subject specialists permits interpretive access to a physically unified collection with an expertise usually found only in large divisional libraries. There must be a substantive commitment to provide subject specialists with salaries and job mobility equivalent to most library administrators. Finally, it will be incumbent upon library educators to evaluate various library position requirements, present and future, in order to design appropriate educational programs.

\section{RefEREnces}

1. Herman H. Fussler, "The Bibliographer Working in a Broad Area of Knowledge," CRL 10:199-202 (July 1949); Cecil K. Byrd, "Subject Specialists in a University Library," CRL 27:191-93 (May 1966).

2. Robert Haro, "The Bibliographer in the Academic Library," Library Resources and Technical Services 13:163-69 (Spring 1969).

3. Richard H. Dillon, "The Phantom of the Library: The Creative Subject Specialist," in Caroline Wire, ed., Library Lectures (Baton Rouge: Louisiana State University Library, 1971), p. 103.
4. David S. Landes and Charles Tilly, History as Social Science (Englewood Cliffs, New Jersey: Prentice-Hall, 1971), p. 103.

5. Robert Stueart, The Area Specialist Bibliographer; An Inquiry Into His Role (Ph.D. dissertation, Univ. of Pittsburgh, 1971), p. $101,156$.

6. Patrick Wilson, Two Kinds of Power; An Essay on Bibliographical Control (Berkeley: University of California Press, 1968), p. 114-24.

7. Arthur P. Young, "Student Assistants: A Report and a Challenge," RQ 9:295-97 (Summer 1970). 